Research Article

\title{
Experimental Study on Wind Erosion Resistance and Strength of Sands Treated with Microbial-Induced Calcium Carbonate Precipitation
}

\author{
Zhaoyu Wang, ${ }^{1}$ Nan Zhang $\left(\mathbb{D},{ }^{2}\right.$ Jinhua Ding, ${ }^{3}$ Chen Lu, ${ }^{1}$ and Yong Jin ${ }^{1}$ \\ ${ }^{1}$ College of Civil Engineering, Yancheng Institute of Technology, Yancheng, Jiangsu 224051, China \\ ${ }^{2}$ Department of Civil Engineering, The University of Texas at Arlington, Arlington, TX 76019, USA \\ ${ }^{3}$ College of Civil Engineering, Jiangsu University of Science and Technology, Zhenjiang, Jiangsu 212003, China
}

Correspondence should be addressed to Nan Zhang; zhangnanvictor47@hotmail.com

Received 14 January 2018; Revised 22 February 2018; Accepted 13 March 2018; Published 8 April 2018

Academic Editor: Michele Iafisco

Copyright (C) 2018 Zhaoyu Wang et al. This is an open access article distributed under the Creative Commons Attribution License, which permits unrestricted use, distribution, and reproduction in any medium, provided the original work is properly cited.

Wind erosion phenomenon is commonly encountered in desert areas, which is harmful to engineering constructions and environment. This study proposed an innovative microbial-induced calcium carbonate precipitation (MICP) technique to reinforce sands for mitigating natural hazards caused by the wind erosion. A series of small-scale laboratory experiments were performed to evaluate wind erosion resistance of MICP-treated sands with different treatment cycles. The spraying method was used to treat sand specimens, and unconfined compression (UCC) strength tests were also conducted to assess the performance of the MICP technique. Experimental results revealed that the bulk density of treated sand was slightly increased with the number of MICP treatment cycles. Additionally, the wind erosion rate of treated sands was significantly decreased, and the UCC strength was increased (maximum to $4 \mathrm{MPa}$ ) with the number of treatment cycles, which was mainly attributed to the bonding effect from the microbial-induced $\mathrm{CaCO}_{3}$ crystals among sand particles based on the scanning electron microscopy (SEM) analyses. Such effect also facilitated to form a hard protection layer on top of the sand specimen in order to improve the wind erosion resistance of MICP-treated sands. This technique provides an alternative method to mitigate and prevent the aggravation of desertification.

\section{Introduction}

In arid and semiarid areas, wind erosion often leads to sand movement, destruction of agroforestry, and dust storms. Transporting and excavating these sands in geotechnical engineering causes serious environmental problems, such as soil erosion and air and water pollution. China has a vast territory with a quarter of desert area as shown Figure 1. In recent years, the desertification becomes very severe and cannot be ignored in the future. The direct adverse impact of desertification is land desertification and erosion, biological reduction, loss of cultivated land, destruction of cities, and so on. More importantly, some of abovementioned impacts are even unrecoverable. Additionally, the desertification also indirectly causes other natural disasters, such as dust storms, smoke, and fog, in many areas that affect the activity or even harm the health of human beings. Hence, it is of great importance to propose a method to mitigate and prevent the aggravation of desertification for sustainable development.

The main methods for desertification control are windbreaks and sand-fixing, such as plant of vegetation and wind-shield walls. In the case of vegetation, plants are less viable due to less amount of water in desert [1], which requires much maintenance or additional cost. On the other hand, wind-shield wall is likely to cause very serious environmental pollution, and the quality of wall construction cannot be guaranteed owing to the severely adverse working conditions. Thus, both these methods have some shortcomings including high maintenance costs, low durability, and potential environmental pollution.

Microbial-induced calcium carbonate precipitation (MICP) technique is considered as an environmental and ecological 


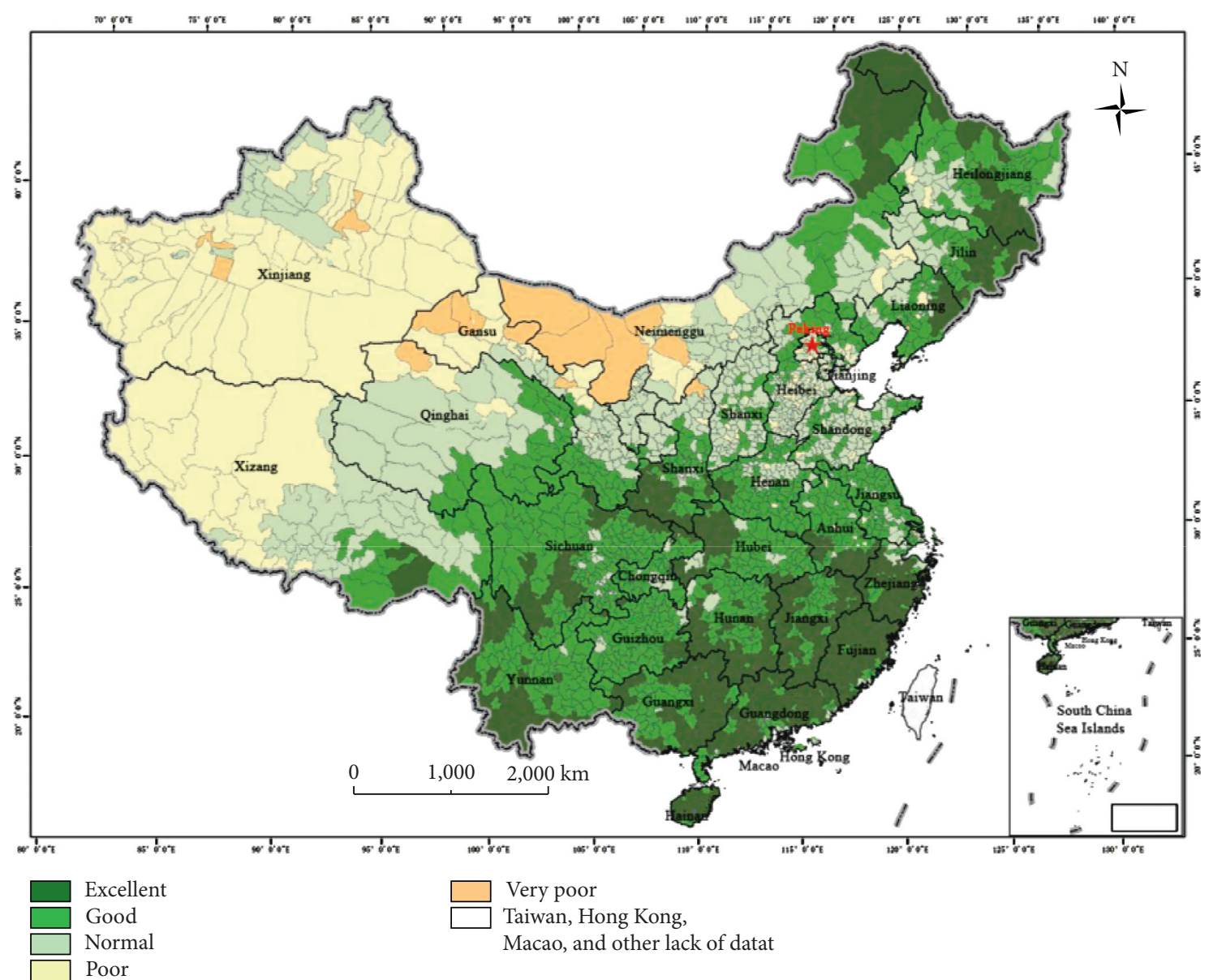

Figure 1: Map of desert distribution in China.

friendly ground improvement and soil reinforcement method [2]. By spraying bacteria and cementation solutions onto the surface of sands, calcium carbonate $\left(\mathrm{CaCO}_{3}\right)$ is generated and rapidly precipitated into the pore space among sand particles. $\mathrm{CaCO}_{3}$ also crystallizes in sand pore space as moisture evaporates, eventually increasing the strength of MICP-treated sand, then improving its geotechnical properties [3]. Among the techniques of microbial mineralization, urea hydrolysis has been widely used $[4,5]$. The urea-hydrolyzed MICP technique is generally based on urease-producing Bacillus cereus, which uses urea as a source of energy to generate numerous highly active ureases through its own metabolic activity, which hydrolyzes urea to produce $\mathrm{NH}_{4}{ }^{+}$and $\mathrm{CO}_{3}{ }^{2-}$. Microbial treatment for reinforcing sands is due to the production of urea generating $\mathrm{CaCO}_{3}$ under the environment of high concentrations of calcium and ammonium ions [6] as shown in Figure 2. The reaction equation is as follows [7]:

$$
\begin{aligned}
& \mathrm{CO}\left(\mathrm{NH}_{2}\right)_{2}+2 \mathrm{H}_{2} \mathrm{O} \rightarrow 2 \mathrm{NH}_{4}^{+}+\mathrm{CO}_{3}^{2-} \\
& \mathrm{Ca}^{2+}+\mathrm{CO}_{3}^{2-} \rightarrow \mathrm{CaCO}_{3} \downarrow
\end{aligned}
$$

As reported [8-12], the use of the MICP technique to reinforce sandy soils to improve the soil structure is satisfactory under various environmental conditions. Also, this technique can effectively increase the stiffness, the bearing capacity, and the liquefaction resistance of sandy soils as well as maintain a certain degree of permeability. Moreover, the use of this method to improve soils will not cause any potential environmental pollution as compared to some traditional soil/ground improvement methods using additives such as fly ash, cement, and lime.

Control of soil erosion and dust requires a definition of "effectiveness" of the dust control agent to evaluate the soil's ability to resist erosion on its top surface [13], but the commonly used dust control agents are generally more costly and less durable, and it may pollute environment. Bang et al. [14] adopted the MICP technique to reinforce sandy soils by spraying bacteria and cementation solutions onto the surface of the sand specimen. It is found that a consolidated thin layer with a certain stiffness was formed at shallow depth of sands after treatment, which demonstrated the MICP technique can effectively improved the wind erosion resistance of sands and suppressed dust. Maryam et al. [15] treated dust samples using biological cement solution and then placed the specimens into a rectangular parallelepiped container to perform a wind blowing test. The results showed that the use of biological cement in dust specimens can significantly reduce the mass loss of dust.

In this study, a series of small-scale laboratory experiments were conducted to reinforce sand using the MICP technique with bacteria and cementation solutions sprayed on top surface of the sand specimen. Then, wind erosion 


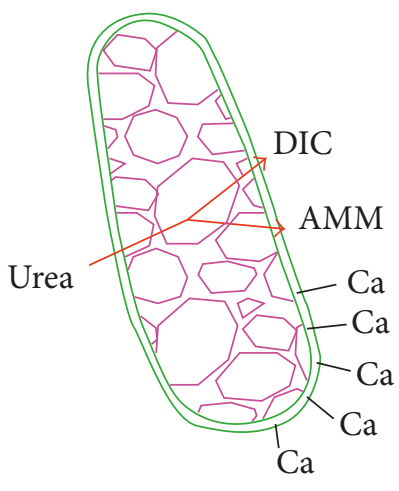

(a)

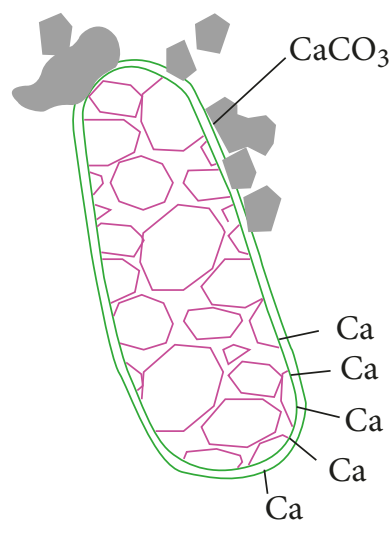

(b)

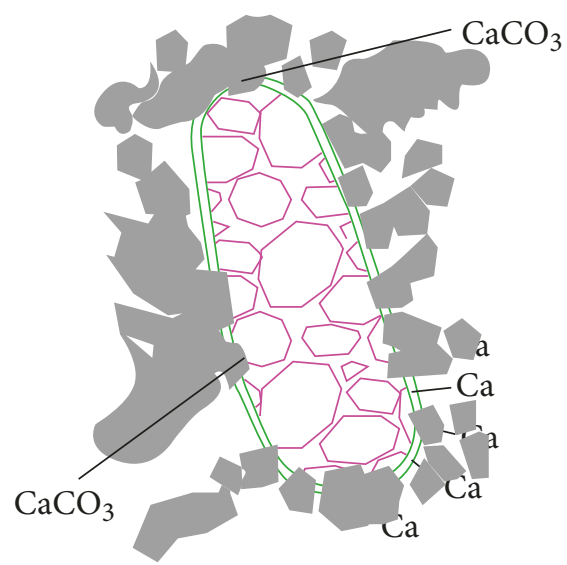

(c)

Figure 2: Microbes provide nucleation sites for the deposition of $\mathrm{CaCO} 3$.

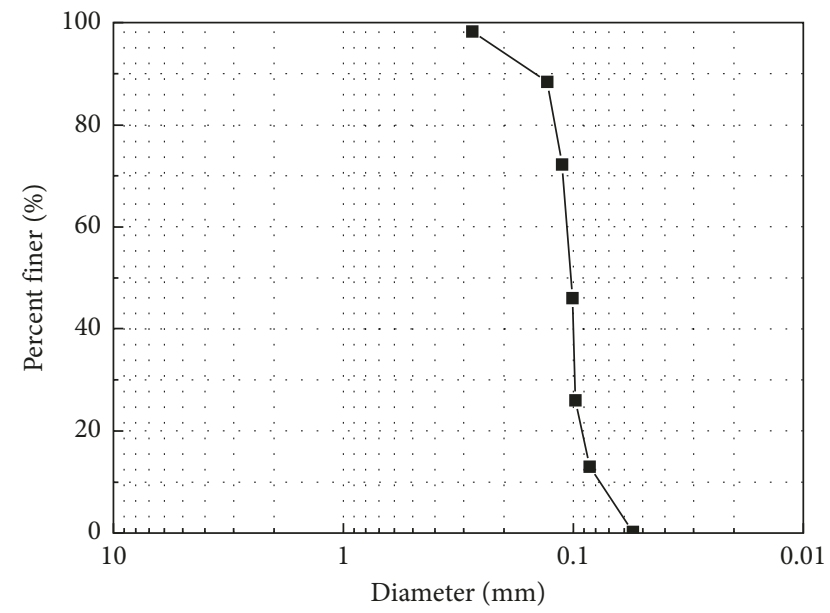

Figure 3: Grain size distribution of test sand.

resistance tests and unconfined compression (UCC) strength tests were performed to investigate the performance of MICPtreated sands. The bulk density, the wind erosion rate, and the UCC strength of treated sands were measured and presented. Scanning electron microscopy (SEM) technique was also used to further analyze the mechanism of MICP reinforcement and improvement of wind erosion resistance of MICP-treated sands.

\section{Materials and Methods}

2.1. Materials. The sand used in this study is poorly graded silica sand. The gradation curve of the sand is shown in Figure 3 . It is indicated that the median grain size $\left(D_{50}\right)$ was $0.1 \mathrm{~mm}$, the coefficient of nonuniformity $\left(C_{\mathrm{u}}\right)$ was 2.5 , and the coefficient of curvature $\left(C_{\mathrm{c}}\right)$ was 0.51 . In addition, the specific gravity of sand was 2.60 and the minimum $\left(e_{\min }\right)$ and maximum $\left(e_{\max }\right)$ void ratios were 0.61 and 0.73 , respectively.

The selected bacteria in this study was Bacillus cereus (i.e., Sporosarcina pasteurii, No. ATCC 11859). The main components of the culture medium included trypsin, soybean peptone, $\mathrm{NaCl}$, urea, and distilled water. The mass of each
TABLE 1: Mass of each component in nutrient solution of $300 \mathrm{~mL}$.

\begin{tabular}{lc}
\hline Materials & Mass \\
\hline Distilled water & $300 \mathrm{ml}$ \\
Trypsin & $4.5 \mathrm{~g}$ \\
Soybean peptone & $1.5 \mathrm{~g}$ \\
$\mathrm{NaCl}$ & $1.5 \mathrm{~g}$ \\
Urea & $6 \mathrm{~g}$ \\
\hline
\end{tabular}

TABle 2: Mass of each component in cementation solution of $300 \mathrm{~mL}$.

\begin{tabular}{lc}
\hline Materials & Mass \\
\hline Distilled water & $300 \mathrm{ml}$ \\
Urea & $18 \mathrm{~g}$ \\
Anhydrous $\mathrm{CaCl}_{2}$ & $33.3 \mathrm{~g}$ \\
\hline
\end{tabular}

component in the bacterial solution is shown in Table 1. Cementation solution was urea- $\mathrm{CaCl}_{2}$ solution with a concentration of $1 \mathrm{~mol} / \mathrm{L}$. Urea provides energy for the growth of microorganisms and sufficient carbonate ions, and the $\mathrm{CaCl}_{2}$ solution provides sufficient calcium ions for $\mathrm{CaCO}_{3}$ precipitation. The mass of each component in cementation solution is shown in Table 2.

The bacteria is needed to be cultivated and activated in the first step. Each component in the culture medium was mixed thoroughly and dissolved in distilled water with $\mathrm{pH}$ adjusted to 7.0-7.5. Then, it was transferred into the sterilization pot for $20 \mathrm{~min}$ at $121^{\circ} \mathrm{C}$ and cooled down for $15 \mathrm{~min}$ in the freezer. The bacterial solution was injected and placed in a shaker for $30 \mathrm{hrs}$ at $30^{\circ} \mathrm{C}$. Then, the bacterial solution was removed which was obviously turbid compared with that before the culture. It is noted that the $\mathrm{OD}_{600}$ value of each bacterial solution was greater than 1.8 , and the electrical conductivity was about $6.275 \mathrm{~ms} / \mathrm{cm}$. The activity of monomer enzyme was about $1.1 \mathrm{~ms} / \mathrm{cm}$ (min.OD).

\subsection{Test Methods}

2.2.1. MICP Tests. Four test sand specimens (no. 1 to no. 4) were prepared with different MICP spraying treatment cycles. 
It is noted that the specimen number was identical to the number of treatment cycles. The sand specimen (no. 0) was also prepared with only water treatment to compare with the MICP-treated specimen.

The test sand was first air-dried and then transferred into a tray with the dimension of $288 \mathrm{~mm} \times 225 \mathrm{~mm} \times 25 \mathrm{~mm}$. The thickness and mass of the tray were $2 \mathrm{~mm}$ and $115 \mathrm{~g}$, respectively. Five percolation holes of diameter of $8 \mathrm{~mm}$ were designed and fabricated at bottom of the tray for draining purpose. A six-layer gauze was placed inside the tray above the holes to prevent sand from draining out of the tray. Then, predetermined mass of dry sand was placed in one layer at bottom of the tray and compacted using a steel rod. The initial dimension of the sand specimen was $263 \mathrm{~mm} \times 200 \mathrm{~mm} \times 10 \mathrm{~mm}$, so the total volume of the specimen $(V)$ was $520 \mathrm{~cm}^{3}$. The initial mass of the sand specimen $\left(M_{0}\right)$ was $820 \mathrm{~g}$, and the void ratio was 0.51 .

Test procedures of using the MICP technique to treat the sand specimen are described below:

(1) Water of $300 \mathrm{ml}$ was used to spray the five sand specimens (no. 0 to no. 5) from the top surface at a rate of $15 \mathrm{ml} / \mathrm{min}$ and then left for $12 \mathrm{hrs}$ under laboratory condition to ensure that the pore space in sands was completely filled with water. This step is aimed at allowing the microorganisms to better adhere to sand particles in the following steps.

(2) Bacterial solution of $300 \mathrm{ml}$ was uniformly sprayed onto the four sand specimens (no. 1 to no. 4) from the top surface at the rate of $15 \mathrm{ml} / \mathrm{min}$, while specimen no. 0 was treated with water simultaneously. All the sand specimens were then left for $4 \mathrm{hrs}$ after treatment to allow the bacterial solution uniformly distributed among sand particles.

(3) Cementation solution of $300 \mathrm{ml}$ was then sprayed onto the four sand specimens (no. 1 to no. 4) from the top surface at the rate of $15 \mathrm{ml} / \mathrm{min}$, while specimen no. 0 was treated with water in the same way as described in the previous step. The specimens were then left for $4 \mathrm{hr}$ to allow thorough reaction of two solutions. Step (2) and (3) were considered as one MICP treatment cycle.

(4) Test procedures (2) and (3) were repeated for specimen nos. 2, 3, and 4. And water treatment was also conducted on specimen no. 0 in the same way as mentioned above.

(5) Microbial-treated sand specimens were cured in laboratory at a temperature of $20^{\circ} \mathrm{C} \pm 2{ }^{\circ} \mathrm{C}$ and relative humidity of $95 \%$ for 28 days.

After curing the specimen for 28 days, the mass of each sand specimen (including the sand specimen and the tray) was weighed and denoted as $M_{28}$. The densities of the specimens were then calculated as below:

$$
\rho=\frac{\left(M_{28}-m\right)}{V}
$$

where $\rho$ is the bulk density of the sand specimen $\left(\mathrm{g} / \mathrm{cm}^{3}\right)$, $M_{28}$ is the total mass of the sand specimen and the tray after curing for 28 days (g), $m$ is the mass of the tray (g), and $V$ is the volume of the specimen $\left(\mathrm{cm}^{3}\right)$.

2.2.2. Wind Erosion Resistance Tests. The experimental setup of the fan downstream was divided into three sections: strong wind section, test section, and diffusion section [16]. The strong wind section was $1000 \mathrm{~mm}$ in length and less than $400 \mathrm{~mm}$ in width; thereby, it was difficult to ensure the stability of the tray. For the test section, the length was $400 \mathrm{~mm}$ and the width was greater than $400 \mathrm{~mm}$, so air condition was relatively stable and wind speed was more uniform. The diffusion section was more open in space, which may lead to uneven air flow. To ensure the uniform air flow, the tests were conducted in a large area $(5 \mathrm{~m} \times 3 \mathrm{~m})$ in the laboratory.

The fan used in the tests was a duct fan with a rated speed of $2800 \mathrm{rpm}$ and an air volume of $3000 \mathrm{~m}^{3} / \mathrm{h}$. In order to avoid the movement of the tray during the tests, the tray was fixed before starting the tests to ensure that the air flow travelling through the top surface of the sand specimen was consistent throughout the test period. It is noted that the sand specimen was placed in the middle of the test section, and the test duration was $90 \mathrm{~min}$ in this study.

Procedures of wind erosion resistance tests are described below:

(1) After curing the specimen for 28 days, the mass of each sand specimen (including the sand specimen and the tray) was weighed and denoted as $M_{28}$.

(2) The sand specimen along with the tray was placed in the test section that is in the downstream of the fan.

(3) The fan was turned on to start the wind erosion resistance test. The total mass of the sand specimen and the tray $\left(M_{i}\right)$ was measured at 5 min interval in $30 \mathrm{~min}$ and at $30 \mathrm{~min}$ interval between $30 \mathrm{~min}$ and $90 \mathrm{~min}$. The amount of wind erosion $(\Delta M)$ was then calculated by $\Delta M=M_{28}-M_{i}$; the wind erosion rate (a) was calculated by $a=\left(M_{28}-M_{i}\right) /\left(M_{28}-m\right)$.

(4) The fan was turned off at 90 min upon completion of the test. The five sand specimens were observed and compared to analyze wind erosion resistance of MICP-treated sands.

(5) In order to clarify the mechanism of solidification and cementation of MICP treatment on sands, a representative sand specimen was taken at shallow depth after the wind erosion resistance tests to perform scanning electron microscopy (SEM) analyses.

2.2.3. Unconfined Compression (UCC) Strength Tests. Because of the severe wind erosion in desert due to the wind storm, it is required that the reinforced sandy soils must reach a certain strength (greater than $1 \mathrm{MPa}$ ) in order to resist wind erosion. Four cylindrical sand specimens (i.e., no. 1 to no. 4) with $30 \mathrm{~mm}$ in diameter and $60 \mathrm{~mm}$ in height were prepared with different MICP spraying treatment cycles.

Test procedures of the UCC strength tests are as follows:

(1) Four syringes with an inner diameter of $30 \mathrm{~mm}$ and a height of $110 \mathrm{~mm}$ were selected to prepare the 


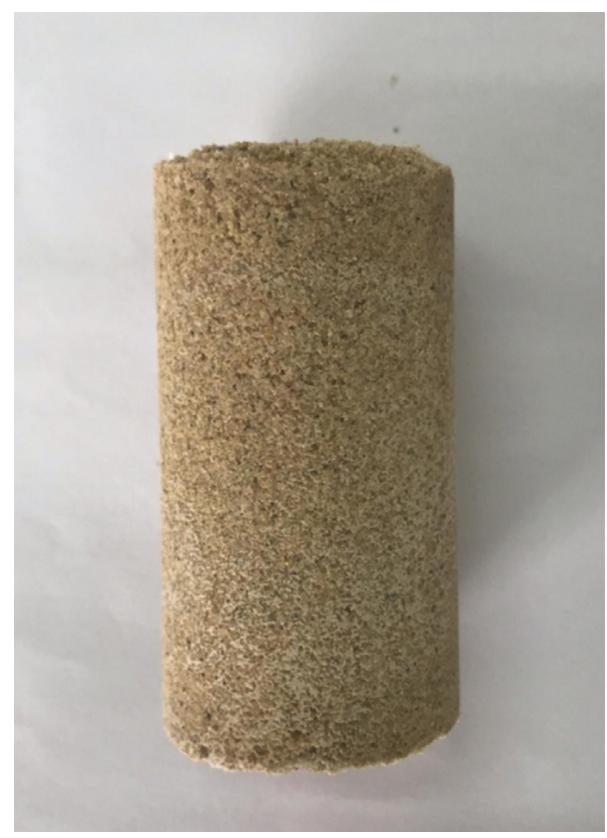

(a)

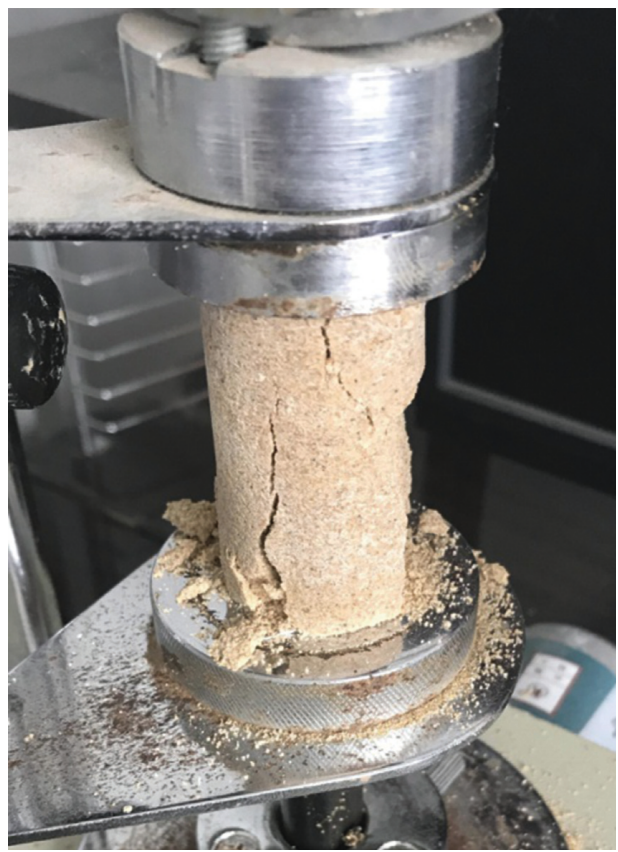

(c)

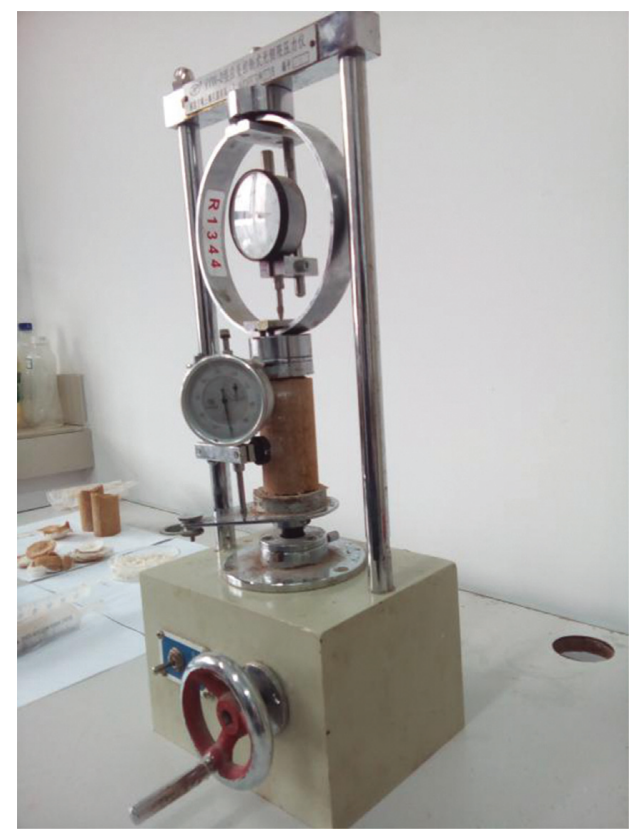

(b)

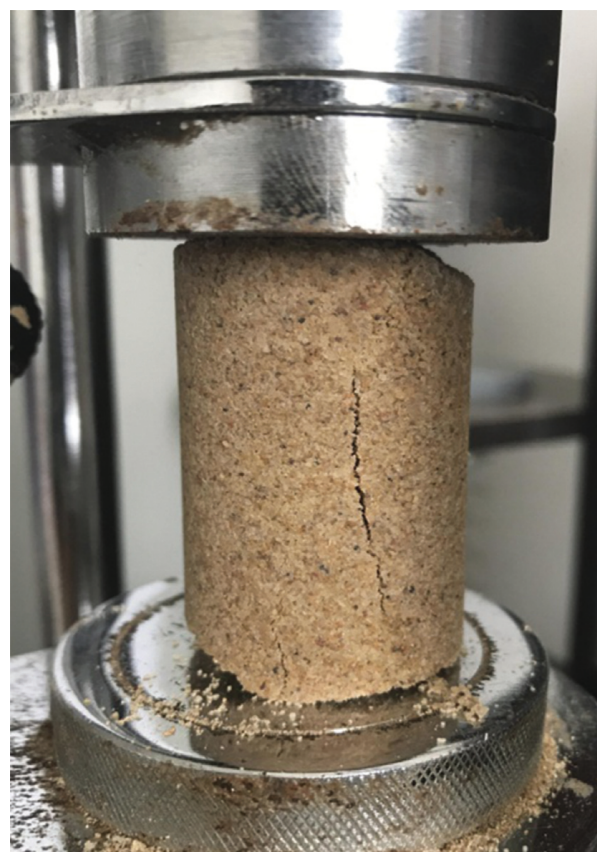

(d)

Figure 4: Photo of unconfined compression (UCC) strength tests: (a) MICP-treated sand specimen; (b) test setup; (c) specimen no. 3 at failure; (d) specimen no. 4 at failure.

cylindrical sand specimen. Four layers of gauze were first placed at the bottom of the syringe. The test sand was then poured into the syringe and slightly compacted by a steel rod to a level top surface. The height of the sand specimen was $60 \mathrm{~mm}$ from the bottom of the syringe. The experimental setup is shown in Figure 4.

(2) Water of $25 \mathrm{ml}$ was used to spray the four sand specimens (no. 1 to no. 4) from the top surface at a rate of $15 \mathrm{ml} / \mathrm{min}$ and then left for $12 \mathrm{hrs}$ under laboratory condition to ensure the pore space was completely filled with water in sands.

(3) Similar to the test procedures of MICP tests, bacterial solution and cementation solution of $25 \mathrm{ml}$ were uniformly sprayed onto the sand specimen (no. 1 to no. 4) from the top surface at the rate of $15 \mathrm{ml} / \mathrm{min}$. All the sand specimens were then left for $4 \mathrm{hrs}$ and then cured in laboratory at a temperature of $20^{\circ} \mathrm{C} \pm 2^{\circ} \mathrm{C}$ and 


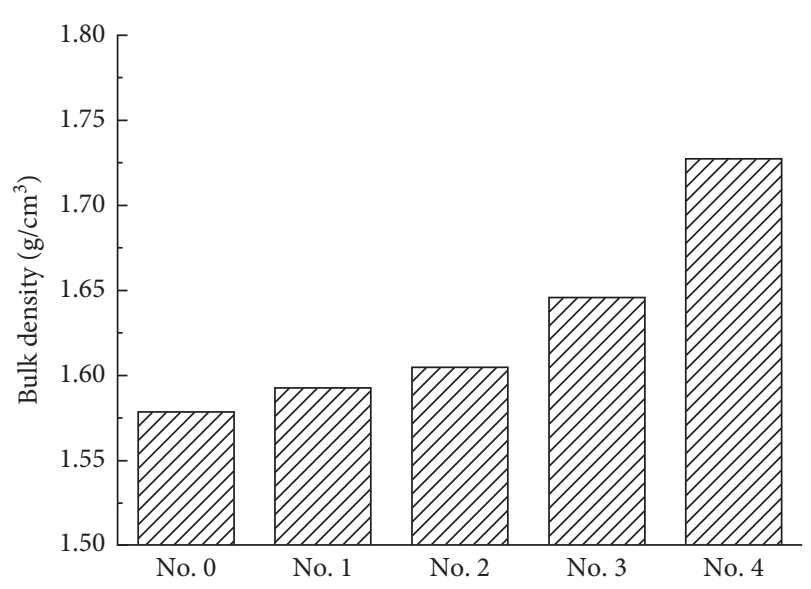

FIGURE 5: Measured bulk density of MICP-treated sand after curing for 28 days.

relative humidity of $95 \%$ for 28 days. Then, test procedures (3) and (4) were repeated for specimen nos. 2 , 3 , and 4 .

(4) The specimen was taken out of the syringe to conduct UCC tests.

\section{Experimental Results}

3.1. Bulk Density. After curing for 28 days, the bulk densities of the five sand specimens were calculated and plotted as shown in Figure 5. It is indicated that the amount of produced $\mathrm{CaCO}_{3}$ by the MICP technique was increased with an increase in the number of MICP treatment cycles. As a result, the pore space in test sand was occupied and densified by $\mathrm{CaCO}_{3}$, so the mass of treated sand specimen was elevated after treatment. Since the thickness and dimensions of the treated sand specimen remained the same, the bulk density was increased accordingly. Thus, the bulk density of the treated specimen increased as the number of treatment cycle increased.

3.2. Appearance Analyses. Figure 6(a) presents the appearance of sand specimen no. 0 before and after wind erosion resistance test. Some cracks were clearly observed on top surface of the specimen before the test. It might be because of the excessive evaporation during the curing period. After the wind erosion resistance test, it is indicated that the cracks were fully developed and became even much wider as shown in Figure 6(a). Moreover, loose sand particles were found below the cracks without any cohesion. It is demonstrated that untreated sand specimen has a very low ability to resist wind erosion and cannot be applied in engineering practice in desert areas.

Appearance of sand specimens (no. 1, 2, 3, and 4) before and after wind erosion resistance tests is shown in Figures 6(b) $-6(\mathrm{e})$. It is found that a $2.5 \mathrm{~mm}$ thick hard sand layer was formed on top surface of specimen no. 1 as shown in Figure $6(\mathrm{~b})$. By using the spraying method in the experiments, MICP-induced $\mathrm{CaCO}_{3}$ was precipitated mostly at shallow depth; thereby, the sand particles were bonded together near top surface. However, there were still some small cracks observed before the wind erosion resistance test, and they were extended and widened during the test. In comparison, the thickness of hard sand layer of specimen no. 2 was increased to $3.5 \mathrm{~mm}$ due to the increasing number of treatment cycles, and no sand particles were blown away in the test (Figure 6(c)). Similar phenomenon was also observed for specimen no. 3 as shown in Figure 6(d), and thickness of the top sand layer was $5 \mathrm{~mm}$. But the cracks were smaller and shorter than specimen no. 1 and no. 2, which also proved that the wind erosion resistance of specimen no. 3 was improved to some extent. As shown in Figure 6(e), the thickness of sand layer at top surface for specimen no. 4 was increased to $6 \mathrm{~mm}$ without any obvious cracks. After the wind erosion resistance test, the appearance of the specimen showed no visible change. It is demonstrated that the wind erosion resistance of MICP-treated sand with four treatment cycles was significantly improved.

Because the sand specimen was sprayed by bacterial and cementation solutions from top surface, the microbialinduced precipitation of $\mathrm{CaCO}_{3}$ crystals were most likely to accumulate and aggregate at shallow depth below the top surface of the sand specimen. The $\mathrm{CaCO}_{3}$ content was increased, and finally, relatively hard sand layers were formed near the top surface. Additionally, with the increasing number of microbial treatment cycles, the thickness of sand layer was increased, the cracks observed at top surface were less, and thereby the wind erosion resistance was improved accordingly. Moreover, such hard sand layer at top surface can also protect the loose sand particles at deep depth from wind erosion.

3.3. Wind Erosion Rate. Figure 7 presents the wind erosion rate of MICP-treated sand. It is evident that the erosion rate of the specimen with only water treatment (no. 0) was rapidly increased in the first $20 \mathrm{~min}$ after the wind erosion resistance test started and then almost remained constant at a level of around $10.23 \%$ until the end of the test. Moreover, the wind erosion rate of the untreated sand specimen was much higher than the MICP-treated sands, revealing that its wind erosion resistance was extremely low. Similarly, the erosion rate of specimen no. 1 was also increased in the first 10 min and kept unchanged at around 3.69\% subsequently. It is noted that the abovementioned huge increase of erosion rate in the beginning of the test is mainly because that the loose sand particles were blown away from the tray. In comparison, the erosion rate of specimen no. 2 was only gradually increased with time in the test. Additionally, the erosion rates of specimen nos. 2, 3, and 4 were considerably reduced by $63.97 \%, 94.75 \%$, and $97.76 \%$, respectively, as compared with the untreated specimen (no. 0). It is found that the average decrease of wind erosion rate was around $60.3 \%$ with the each increment of MICP treatment cycle. Consequently, the use of the MICP technique can effectively improve the wind erosion resistance of sands, and such improvement is positively proportional to the number of MICP treatment cycle. 


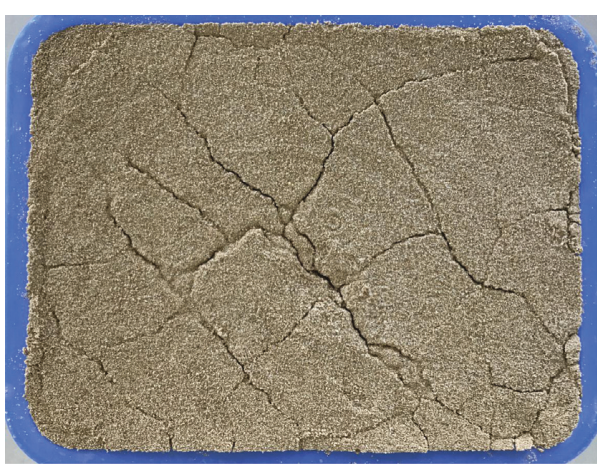

Before wind resistance test

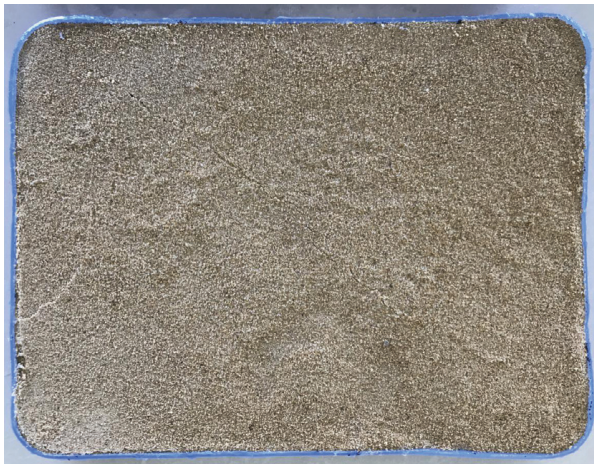

Before wind resistance test

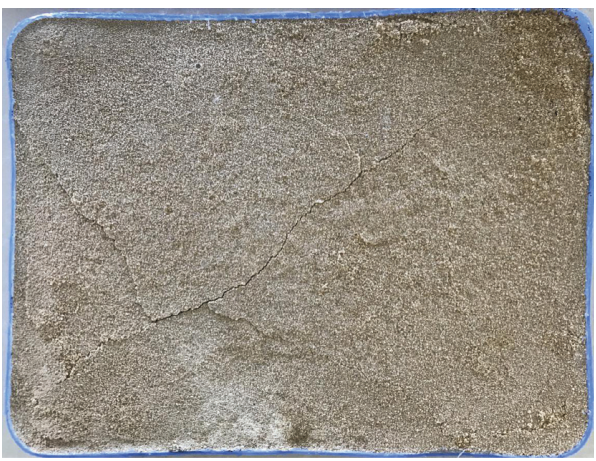

Before wind resistance test

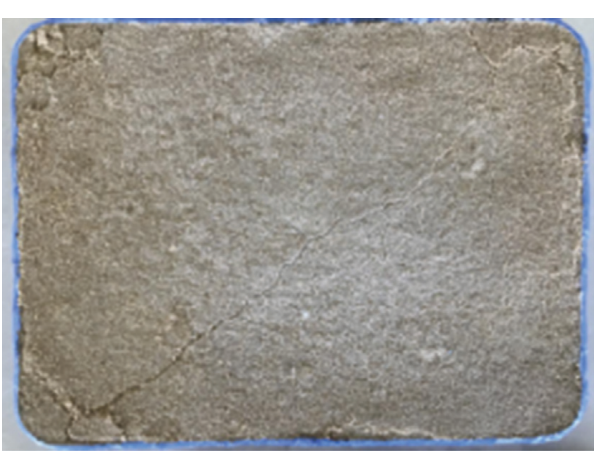

Before wind resistance test

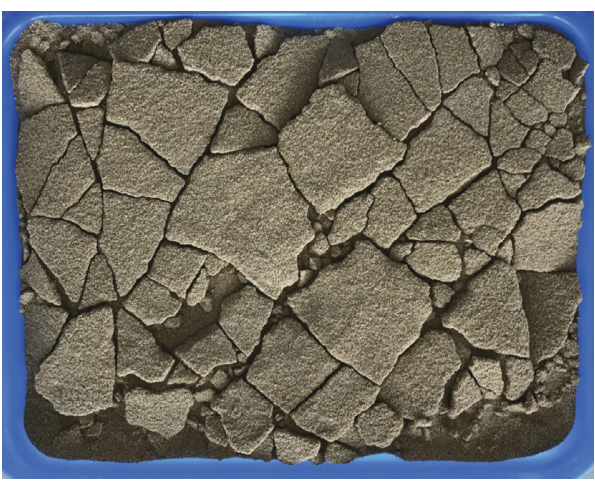

After wind resistance test

(a)

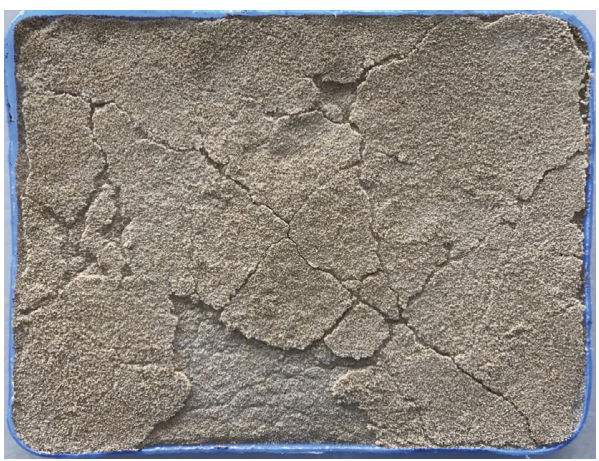

After wind resistance test

(b)

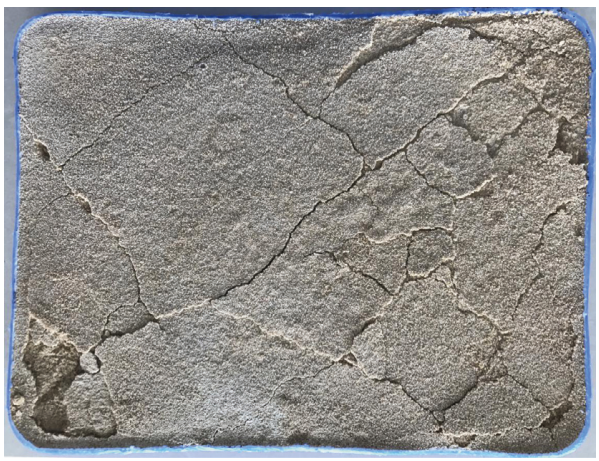

After wind resistance test

(c)

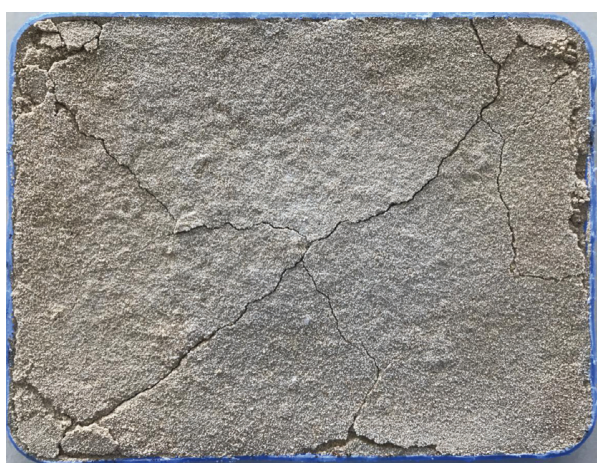

After wind resistance test

(d)

Figure 6: Continued. 


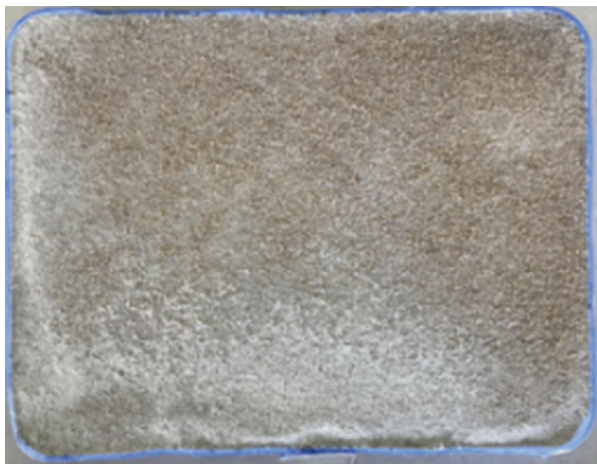

Before wind resistance test

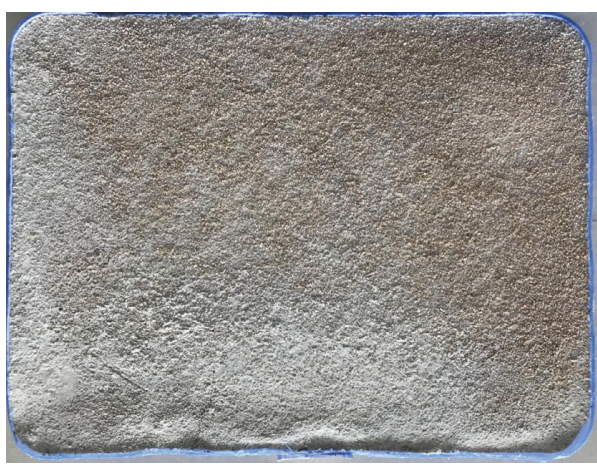

After wind resistance test

(e)

Figure 6: Photos of sand specimens before and after wind resistance tests: (a) no. 0; (b) no. 1; (c) no. 2; (d) no. 3; (e) no. 4.

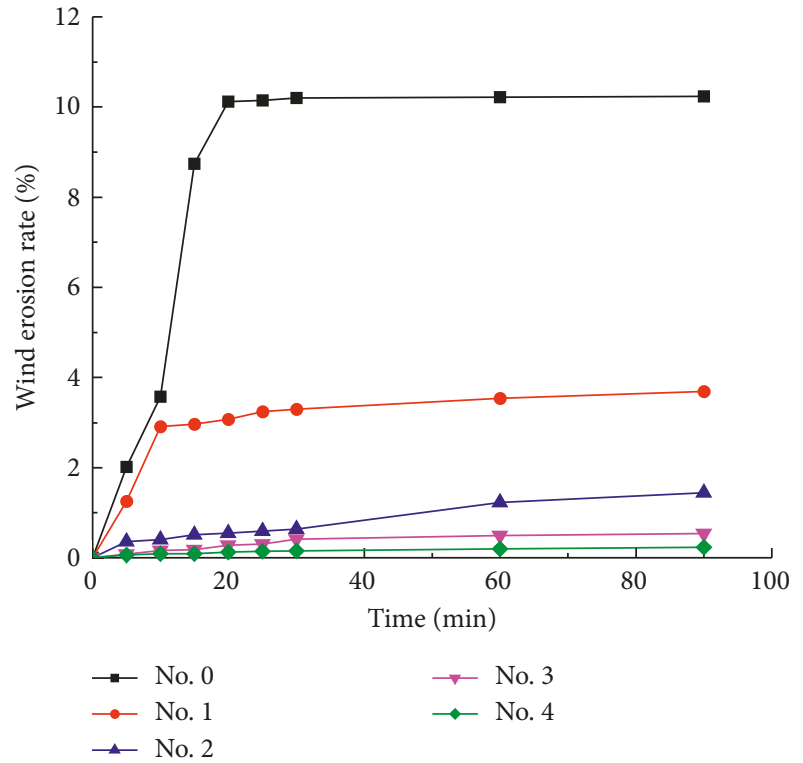

FIGURE 7: Wind erosion rate of MICP-treated sand.

3.4. UCC Strength. During the UCC tests, it was found that as the number of treatment increased, more $\mathrm{CaCO}_{3}$ precipitation in specimen was detected. Brittle failure occurred suddenly on the MICP-treated sand specimen as the deviator stress continued increasing in the tests. After failure occurred, some crushed sand particles collapsed, but some undamaged part of the specimen still maintained a relatively high strength by observation. Figure 8 presents the UCC strength of MICP-treated sands. It is indicated that the average strength of specimen no. 1 and no. 2 was around $1 \mathrm{MPa}$, which was almost three times lower than the strength of specimen no. 3 and no. 4 . This is consistent with the previous experimental results of wind erosion resistance tests. As the number of MICP treatment cycle increases, the content of MICP-induced $\mathrm{CaCO}_{3}$ is increased, leading to a higher bonding strength among sand particles. Thus, the UCC strength of the treated sands will be increased.

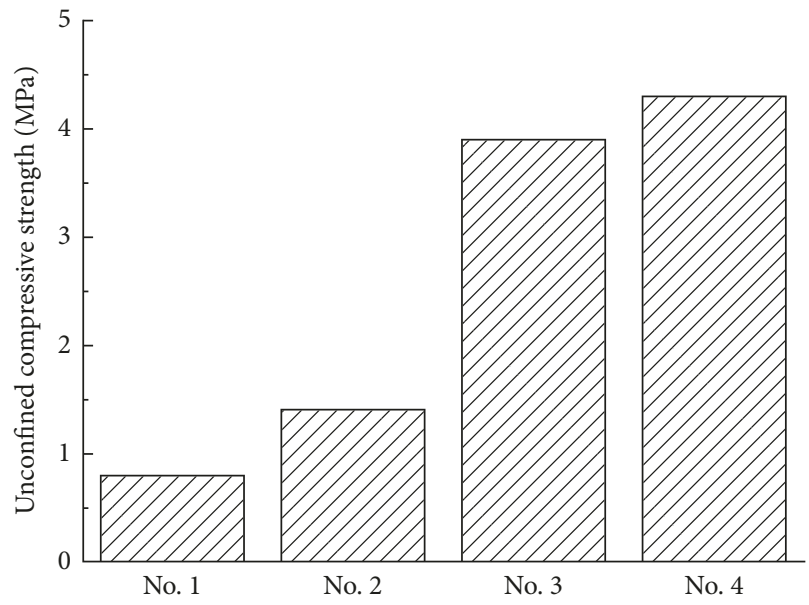

FIgURE 8: UCC strength of MICP-treated sand.

3.5. Scanning Electron Microscopy (SEM) Analyses. In order to investigate the mechanism of solidification and cementation of MICP-treated sand under microscopic conditions, a small amount of sand specimen no. 4 at top surface was used to perform SEM analyses after the wind erosion resistance tests. The underlying mechanism of wind erosion resistance of MICP-treated sands will be clarified in this section.

Figures 9(a) and 9(b) present SEM images of untreated and MICP-treated sands with different magnifications. In Figure 9(a), it is indicated that the sand particles had relatively smooth surface without any adhered materials and were separated with each other; thereby, there was no bonding among them in untreated sands. As shown in Figure 9(b), the surface of the sand particles was rough, the pore space among the particles became smaller, and the sand particles were bonded together as a whole soil body. As shown in Figure 9(c), it is found that small MICP-induced $\mathrm{CaCO}_{3}$ crystals generated on the surface of sand was densely packed on the surface of sand particles. Moreover, it is also observed that the $\mathrm{CaCO}_{3}$ crystals were aggregated at particle contact points, which is because the microorganism is more easily adsorbed in a relatively small space. This phenomenon 


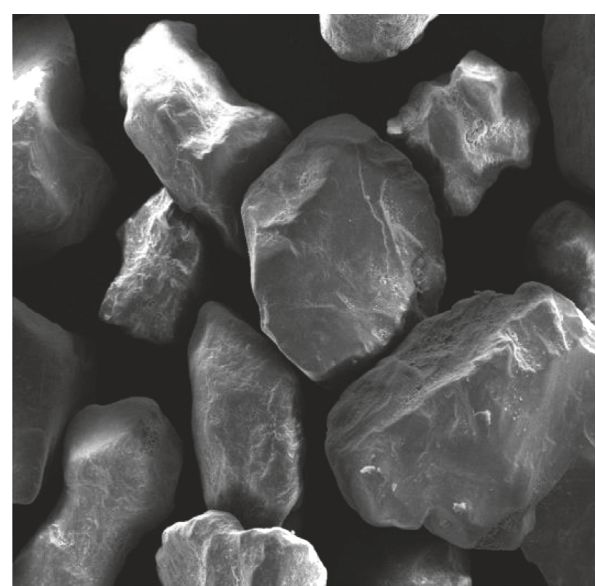

(a)

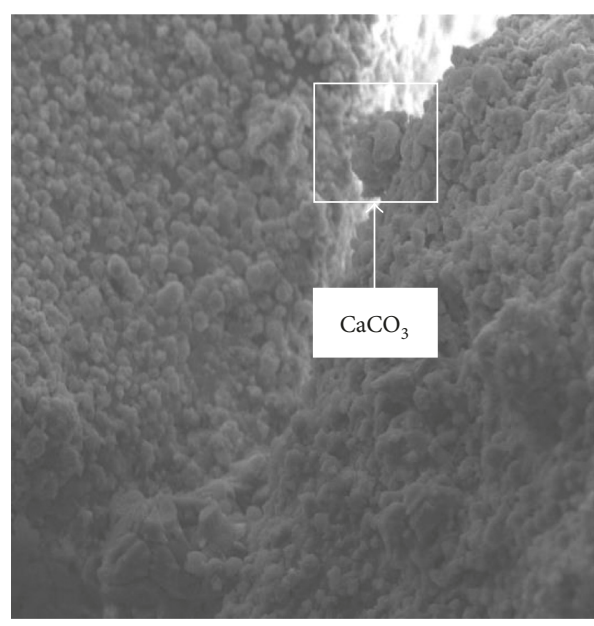

(c)

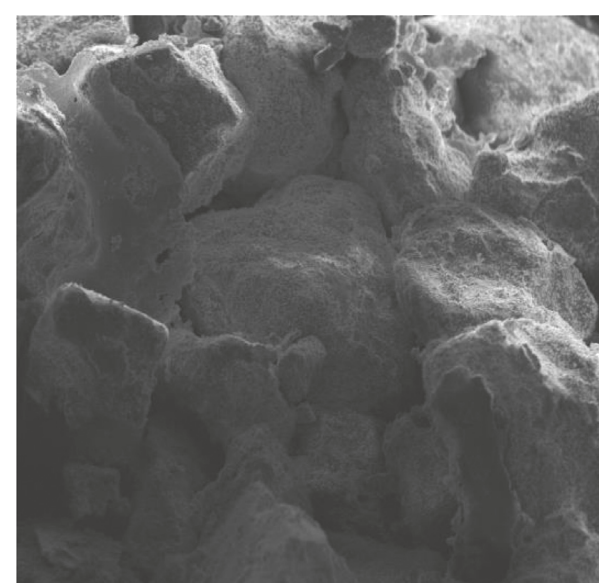

(b)

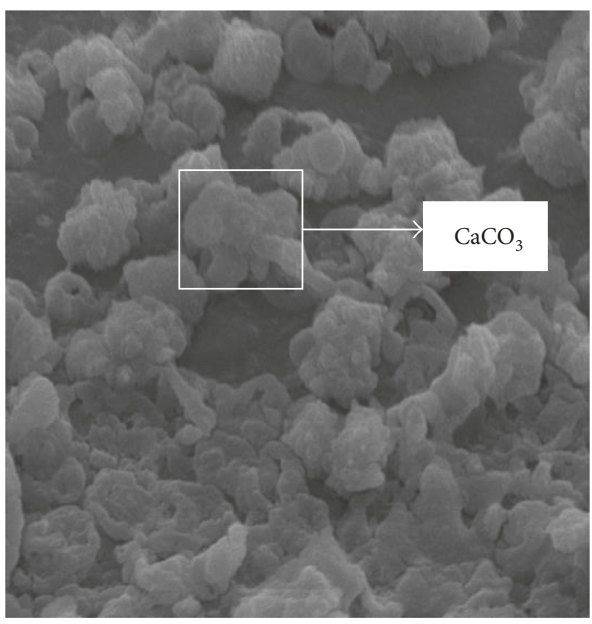

(d)

FIGURE 9: SEM images of sands: (a) untreated sands with magnification at 300x; (b) treated sands with magnification at 300x; (c) treated sands with magnification at $1500 \mathrm{x}$; (d) treated sands with magnification at 10000x.

also demonstrates that the $\mathrm{CaCO}_{3}$ crystals induced by the MICP technique among sand particles is the main cause of increase in strength of the MICP-treated sand, and it also clarifies the mechanism of using the MICP technique to reinforce soils. Moreover, the $\mathrm{CaCO}_{3}$ crystals were basically in spherical shape adhered on surface of sand particles as shown in Figure 9(d),

Figure 10 shows the schematic of sand particles encapsulated by $\mathrm{CaCO}_{3}$ crystals. During the MICP treatment, bacterial solution is first infiltrated into the sand, and the initial sand pore space will be occupied by the bacteria (Sporosarcina pasteurii). The urea is then hydrolyzed to generate $\mathrm{CO}_{3}{ }^{2-}$ through metabolic activity of the bacteria. $\mathrm{CO}_{3}{ }^{2-}$ was transported into surrounding environment and quickly reacted with $\mathrm{Ca}^{2+}$ in the cementation solution to produce $\mathrm{CaCO}_{3}$. Thereafter, a large amount of $\mathrm{CaCO}_{3}$ crystals will be generated from hundreds of thousands of bacteria to fill the sand pore space and bond loose sand particles together as shown in Figure 10. As a result, a hard sand layer is formed on the top surface of the sand specimen that can resist cracking and wind erosion in wind erosion resistance tests as presented in previous sections.

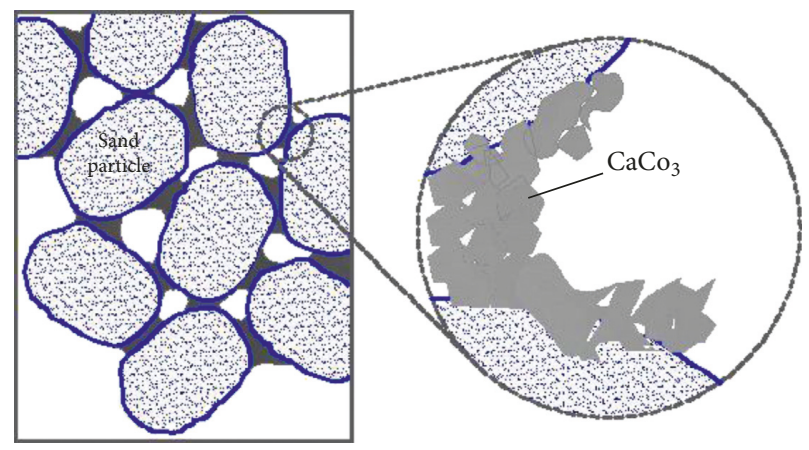

Figure 10: Schematic of sand particles encapsulated by $\mathrm{CaCO}_{3}$ crystals.

\section{Summary and Conclusions}

In this study, a series of small-scale laboratory experiments using the MICP technique and spraying method were conducted on sands to investigate its wind erosion resistance and strength. The main conclusions can be drawn as follows: 
(1) It is feasible to use the MICP technique and the spraying method to reinforce sands for mitigation and prevention of aggravation of desertification. A thin hard sand layer with a certain strength formed on top surface of sand was able to resist cracking and wind erosion and control the diffusion of dust. The thickness and strength of the hard sand layer were increased with the number of MICP treatment cycles.

(2) The wind erosion rate of the untreated sand was as high as $10.23 \%$, whereas it is less than $0.4 \%$ for the treated sand when the number of MICP treatment cycles was more than three. The erosion rate of treated sand with four treatment cycles was reduced by more than $90 \%$ than the untreated sand. Additionally, the UCC strength of MICP-treated sand was more than $4 \mathrm{MPa}$ when the treatment cycles were greater than three.

(3) Based on the SEM analyses, it is concluded that the MICP-induced $\mathrm{CaCO}_{3}$ crystals being formed in sands to fill the pore space and bond sand particles together that significantly contributed to the improvement of UCC strength and wind erosion resistance of MICP-treated sand.

(4) Further study is still needed to investigate the effect of released ammonia on environment in the process of MICP treatment and the durability of MICPtreated sand, including rain scour resistance, aging resistance, and freeze-thaw resistance, for environmental protection and sustainable development.

\section{Data Availability}

The data used to support the findings of this study are available from the corresponding author upon request.

\section{Conflicts of Interest}

The authors declare that there are no conflicts of interest regarding the publication of this paper.

\section{Acknowledgments}

This research was financially supported by the Natural Science Foundation of Jiangsu Province (Grant no. BK20161311), the Joint Technology Transfer Center of Yancheng Vocational Institute of Industry Technology, Yancheng Polytechnic College (Grant no. YGKF-201705) the Innovation of Science and Technology of Institution of Higher Education in Jiangsu Province (Grant no. 2017-51), and the Six Major Talent Peak in Jiangsu Province in China (Grant no. 2015-JZ-011).

\section{References}

[1] W. B. William, D. C. Coleman, and W. J. Wiebe, "Prokaryotes: the unseen majority," Proceedings of the National Academy of Sciences of the United States of America, vol. 95, no. 12, pp. 6578-6583, 1998.
[2] Z. Y. Wang, N. Zhang, G. J. Cai, Y. Jin, N. Ding, and D. J. Shen, "Review of ground improvement using microbial induced carbonate precipitation (MICP)," Marine Georesources \& Geotechnology, vol. 35, no. 8, pp. 1135-1146, 2017.

[3] J. T. Dejong, K. S. Soga, E. Kavazanjian et al., "Biogeochemical processes and geotechnical applications: progress, opportunities and challenges," Geotechnique, vol. 63, no. 4, pp. 287-301, 2013.

[4] C. X. Qian, A. H. Wang, and X. Wang, "Study on microbial grouting reinforcement soil," Rock and Soil Mechanics, vol. 36, no. 6, pp. 1537-1548, 2015, in Chinese.

[5] J. T. DeJong, B. M. Mortensen, B. C. Martinez, and D. C. Nelson, "Biomediated soil improvement," Ecological Engineering, vol. 36, no. 2, pp. 197-210, 2010.

[6] D. W. Muynck, D. N. Belie, and W. Verstraete, "Microbial carbonate precipitation in construction materials: a review," Ecological Engineering, vol. 36, no. 2, pp. 118-136, 2010.

[7] M. B. Burbank, T. J. Weaver, T. L. Green, B. C. Williams, and R. L. Crawford, "Precipitation of calcite by indigenous microorganisms to strengthen liquefiable soils," Geomicrobiology Journal, vol. 28, no. 4, pp. 301-312, 2011.

[8] J. T. DeJong, M. B. Fritzges, and K. Nusslein, "Microbially induced cementation to control sand response to undrained shear," Journal of Geotechnical and Geoenvironmental Engineering, vol. 132, no. 11, pp. 1381-1392, 2006.

[9] C. Chou, E. A. Seagren, A. H. Aydilek, and M. Lai, "Biocalcification of sand through ureolysis," Journal of Geotechnical and Geoenvironmental Engineering, vol. 137, no. 12, pp. 1179-1189, 2011.

[10] J. Du and D. Zhou, "Experimental study on microbial improved expansive soil," Water Resources and Hydropower Engineering, vol. 43, no. 7, pp. 103-105, 2012.

[11] M. J. Jiang, Y. P. Zhou, and C. He, "Experimental study on mechanical properties of intergranular cementation with different cementation thicknesses," Rock and Soil Mechanics, vol. 34, no. 5, pp. 1264-1273, 2013, in Chinese.

[12] J. Chu, V. Ivanov, M. Naeimi, V. Stabnikov, and H.-L. Liu, "Optimization of calcium-based bioclogging and biocementation of sand," Acta Geotechnica, vol. 9, no. 2, pp. 277-285, 2014.

[13] T. Piechota, J. Vanee, J. Batista et al., Potential Environmental Impacts of Dust Suppressants: "Avoiding Another Times Beach": An Expert Panel Summary, U.S. Environmental Protection Agency, Dust Control, 2004, Las Vegas, NV, USA, 2002.

[14] S. Bang, S. H. Min, and S. S. Bang, "Application of microbiologically induced soil stabilization technique for dust suppression," International Journal of Geo-Engineering, vol. 3, no. 2, pp. 27-37, 2011.

[15] N. Maryam, "Biocementation of sand in geotechnical engineering," CEE Dissertation, Nanyang Technological University, Singapore, 2014.

[16] D. He and X. W. Liu, "Experimental methods of wind tunnel in the study of deserts," Geographical Research, vol. 2, no. 4, pp. 99-107, 1983, in Chinese. 


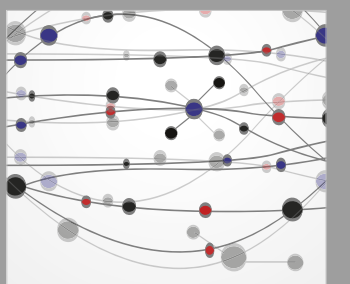

The Scientific World Journal
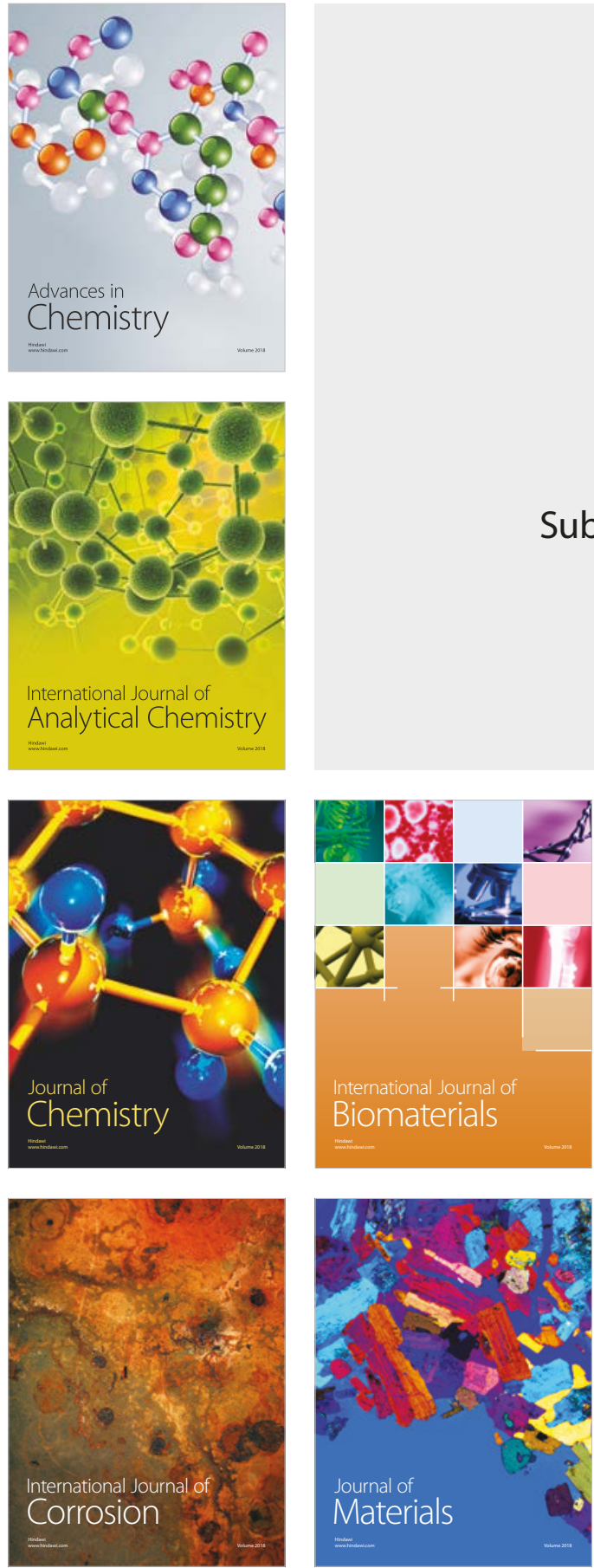

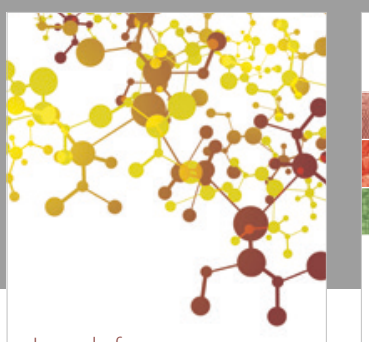

Journal of

Applied Chemistry
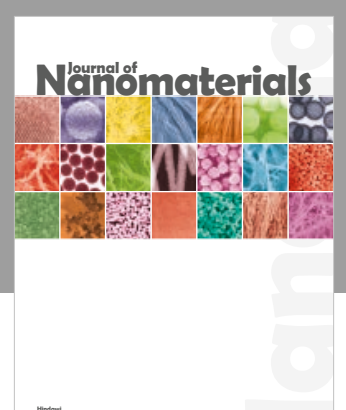

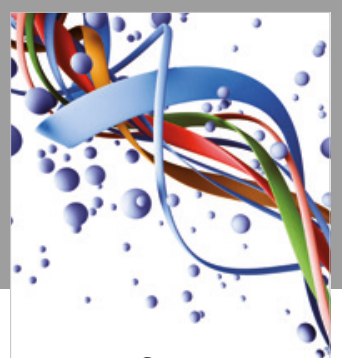

Scientifica

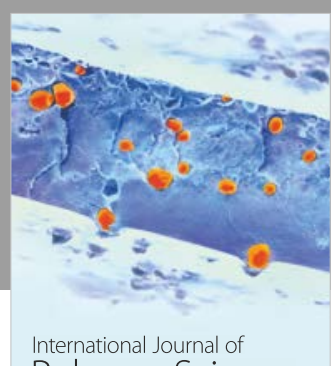

Polymer Science

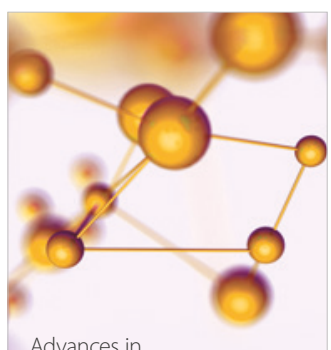

Physical Chemistry
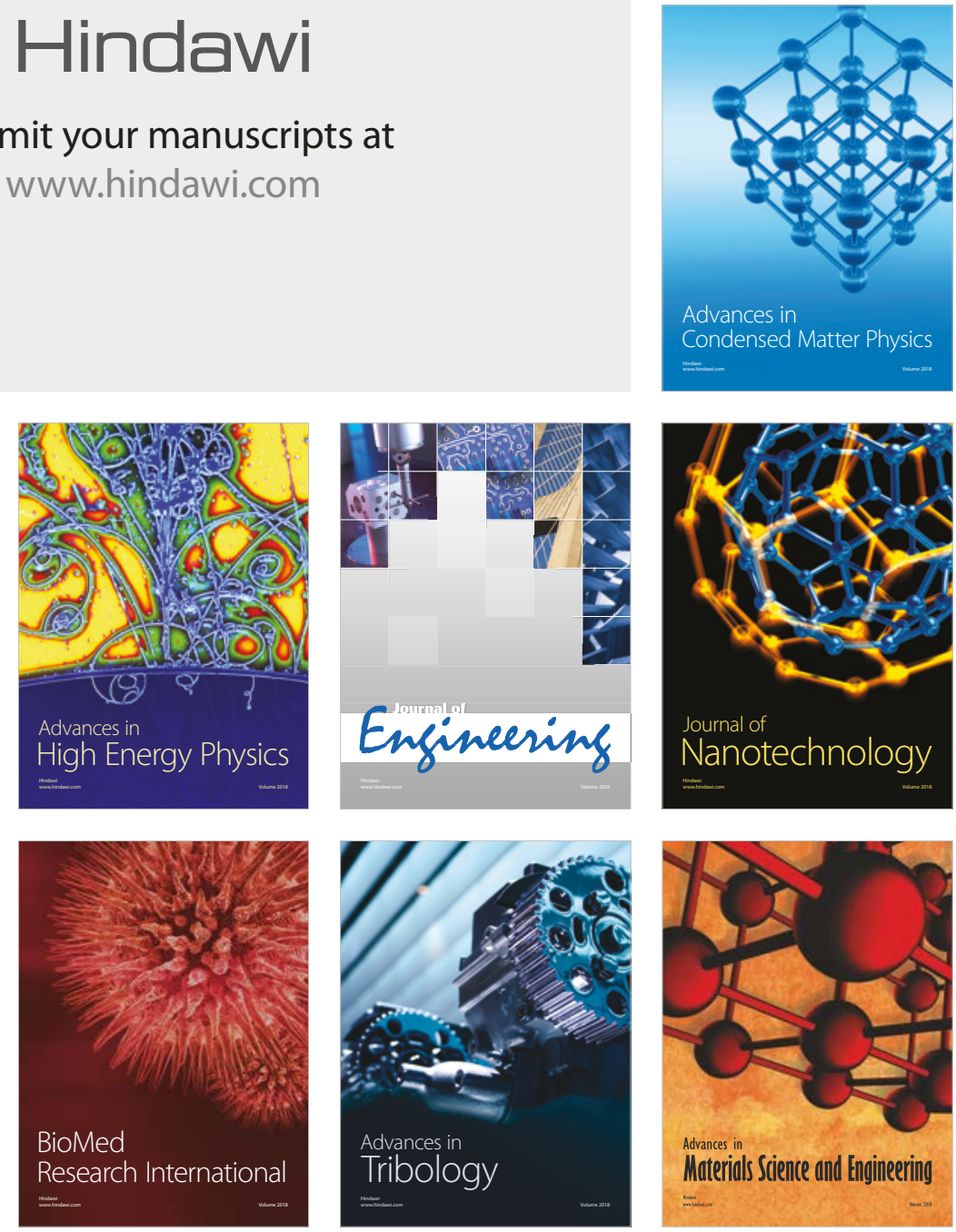